\title{
AIRES DE REFORMAS AL SISTEMA DE SEGURIDAD SOCIAL Y PENSIONES EN COLOMBIA
}

\author{
Martha Elisa Monsalve Cuéllar* \\ Universidad La Gran Colombia de Bogotá, Colombia
}

\section{INTRODUCCIÓN}

Es indiscutible que con la Recomendación N² 202 de 2012, de la O.I.T, los países miembros han comenzado una ola de ajustes en sus legislaciones con miras a seguir los pasos que marca la organización rectora en cuanto a fuentes de financiación de los sistemas de seguridad social en el mundo.

Hemos podido constatar que las formas de financiamiento se han tornado insostenibles por los grandes cambios, no previstos, en la demografía. Así, fenómenos como el envejecimiento poblacional y el desempleo juvenil han venido a incidir grandemente en la desfinanciación del sistema.

Nuestro país no es una excepción, pues ya tenemos normas que acogen la Recomendación de la O.I.T sobre pisos de protección social en la Reforma Tributaria, Ley n 1607 de 2012.

Consideramos que la seguridad social afronta un gran desafío para el siglo XXI desde el punto de vista de su sostenibilidad financiera.

\section{PROPUESTAS DE REFORMA EN SALUD}

El sistema de seguridad social en Colombia presenta un gran contrasentido, pues si bien es cierto cuenta con una cobertura del $90 \%$, entre el sistema subsidiado SISBEN con un $60 \%$ de la población vulnerable y el 30\% en contributivo, cifra que tiende a decrecer dada la tasa del desempleo del 10\%, y que aunque se prevé mediante la Ley n ${ }^{\circ} 1502$ de 2012 la afiliación de los trabajadores independientes a Riesgos Profesionales sin atender al monto de la cotización con base en el salario mínimo legal vigente, la crisis de las EPS’s, Empresas Prestadoras de Servicios en Salud, que en los últimos dos años han afrontado la más aguda crisis de descomposición y abierta corrupción, que hace que muchas de ellas estén intervenidas y sus administradores afronten denuncias de carácter penal.

Todo esto en desmedro del servicio, que no es adecuado y que ha llevado al descrédito del sistema, y que ahora se miraN con escepticismo las propuestas de reforma que se plantean porque aun no contamos con un proyecto consolidado y estamos en una etapa de debates y consultas.

A esto se suma el problema del suministro de medicamentos, que en estos sistemas (tanto el subsidiado como el contributivo) adolece de graves falencias, ya que no se formulan por los

* Doctora en Derecho y Ciencias Políticas, Docente Investigadora Programa de Derecho Universidad La Gran Colombia de Bogotá. 
médicos tratantes, sino por los denominados "genéricos", porque son de bajo costo aunque de menor efectividad ${ }^{1}$.

En un reciente evento internacional celebrado en Bogotá, con motivo de la Semana de la Seguridad Social que institucionalizó la Ley n 1502 de 2012, en que se habló de la "cultura de la seguridad social", Miguel Ángel Fernández Pastor² nos decía que estamos en una "frenética dinámica de cambios", concepto que compartimos, pero no dejamos de anotar que entre más escuchamos sobre el tema, percibimos que no tenemos mucha claridad en los objetivos y ensayamos propuestas no muy consecuentes.

Juan Carlos Cortés González ${ }^{3}$ nos presenta la importancia de estos programas, que ya se inician en las escuelas primarias en Colombia y que estamos llevando a las Universidades como una necesidad de concientización.

Para aumentar la cobertura al 100\% es necesario contar con recursos, y estos provienen, básicamente, del empleador y del trabajador dependiente, pues en el trabajo autónomo no regulado las cotizaciones son francamente utópicas.

El sentido de la Recomendación N²02 de 2012 presupone el "bípode" a que nos hemos referido, y el Estado como tal desaparece de la trilogía en que fue concebido el sistema de Seguridad Social, con lo cual éste pasa a ser únicamente un supervisor de inversiones, un consejero, desvirtuando completamente la concepción inicial de la Seguridad Social. Esto resulta preocupante, pues estamos dejando solamente en empresarios y trabajadores todo el peso del financiamiento del sistema.

Vinculado con lo anterior, también es preocupante la evasión y elusión de aportes a la seguridad social y a los impuestos. Nuestros sistemas de control y supervisión son de una debilidad pasmosa, y allí, infortunadamente, campea olímpicamente una gran corrupción.

"Seguridad social para todos": hemos escuchado tantas veces esta frase que suena como la posibilidad de luchar contra la pobreza absoluta y además contra la inequidad que causa conflictos sociales.

Los Estados de bienestar han sucumbido, especialmente en la Unión Europea. Los considerábamos invulnerables, pero la actual crisis los ha tocado sensiblemente, y si no hubiera sido por la fortaleza del Fondo Previsional en España, para dar un ejemplo, las cosas hubieran sido mucho peores; no obstante, se han tenido que hacer sensibles recortes para no fracasar completamente.

\section{RIESGOS LABORALES}

Íntimamente ligados al régimen de Salud, vemos cómo el Decreto n 723 de 2013 establece, con base en la Declaración de Guatemala, la estrategia de la cultura del "autocuidado" que debe propiciarse desde la escuela primaria, concientizando desde la niñez sobre la importancia de la prevención de todos los riesgos que conlleve a prevenir riesgos laborales cuando se acceda al trabajo, pues ya se lleva esa cultura.

En razón de ello, se establece la afiliación obligatoria a la ARL (Administradora de Riesgos Laborales) a quienes tengan contrato escrito de más de un mes de duración y por intermedio de la entidad de la empresa contratante.

Los costos de los medicamentos en Colombia son altísimos e inalcanzables para un núcleo considerable de población.

Secretario General del CIESS.

Cortés González, Juan Carlos. Estructura de la Protección Social en Colombia. Bogotá, Colombia: LEGIS, 2012. 
El contratista, en el caso de los contratistas independientes, puede escoger su ARL para los riesgos 1, 2 y 3 . En el caso de los riesgos altos, o sea, 3 y 4, se considera la del contratante, quien a su vez reporta las novedades.

Desde el punto de vista de la protección en riesgos laborales, lo consideramos un avance. No obstante, abrigamos serios temores desde el punto de vista de la presunción de una relación laboral. En nuestro concepto se están dejando vigentes elementos de relación laboral que se habían tratado de evitar mediante la figura del contratista independiente.

Por cuenta de innumerables sentencias de nuestra Corte Constitucional se ha dado paso a la "discapacidad manifiesta" que está generando un fuero reforzado de estabilidad que no solamente atenta contra la libre contratación en las empresas de acuerdo con sus necesidades, sino que crea una categoría nueva a cargo de la empresa, la cual no solamente verá afectada su productividad ante la exigencia de mantener vinculados a trabajadores discapacitados, sino que genera una obligatoriedad de un trámite ante el Inspector del Trabajo para solicitar permiso para terminar los contratos de estos trabajadores cuando la empresa lo requiera, debiendo pagar 180 días de salario como indemnización y con un trámite demasiado dilatado, con posibilidades de manejo deshonesto por los funcionarios que de manera fraudulenta pretendan sacar provecho con estas autorizaciones, lo cual ya se ha detectado por empresarios.

\section{SEGURIDAD SOCIAL EN PENSIONES}

No dudamos en calificar el problema del envejecimiento poblacional como endémico y al cual no le habíamos prestado mayor atención.

Por diferentes factores, especialmente la toma de conciencia de la "persona adulta" (denominación de la O.I.T.) tratamos de generalizar la importancia del cuidado preventivo, la práctica del ejercicio corporal, vigilancia de la alimentación y hábitos saludables. Cada día es más evidente una población sensiblemente mayor, como no se apreciaba hace más de 10 años.

Esto llama la atención sobre muchos aspectos a considerar en los cambios que se proponen.

Por ejemplo, el aumento de las edades, pues si se vive más, la edad de pensión debiera aumentarse.

La financiación de los Fondos de Pensiones que fueron ideados para periodos más cortos de reconocimiento de pensiones, una vez aumentada la probabilidad de vida, el disfrute de la pensión será a más largo tiempo y el ahorro de fondos para ello no se realizó. De allí que tengamos semejante desbalance en nuestros sistemas.

Respecto al cuidado de la persona adulta, es necesario prever esta circunstancia, que ha llevado inclusive al completo abandono y desprotección de estas personas por la falta de sitios y personas especializadas en su cuidado o bien teniendo que sacrificar a un miembro de la familia (especialmente a la mujer, que puede interpretarse como discriminación) para que se ocupe de ello, poniendo fin a su vida laboral y a sus aspiraciones de crecimiento, lo que es abiertamente injusto e inequitativo.

Nos preocupa la apatía de los jóvenes frente a la inminencia de la vejez. Nunca piensan en ella como un riesgo a largo plazo. Y ni decir del riesgo de invalidez, que puede ser mucho más próximo que tardío. Hay que crear en ellos esa conciencia y, por tanto, urge la necesidad de construir sus pensiones para el futuro.

Es importante y perentoria la creación de Institutos de Servicios Sociales para Jubilados y Pensionados, en los cuales las entidades financieras de las pingües ganancias, que muestran en 
sus estados de utilidades anuales, destinen partidas importantes para cubrir esta necesidad de la sociedad. ${ }^{4}$

Por ello resulta muy importante poner en vigencia el Envejecimiento Saludable que pregonaba el profesor Sergio Alonso, de la Argentina, en el Encuentro Internacional llevado a cabo los días 23 y 24 de Abril en Bogotá, organizado por CODESS Y CIESS en la Semana de la Seguridad Social.

\section{PROGRAMA FAMILIAR EN ACCIÓN}

En las consideraciones sobre la Ley ${ }^{\circ} 1532$ de 2012, por medio de la cual se adoptan unas medidas de política y se regula el funcionamiento del Programa Familias en Acción ${ }^{5}$, se enfatiza sobre los beneficiarios del programa, radicándolo especialmente en la población vulnerable, a saber: familias en situación de extrema pobreza, desplazados.

No podemos negar la inmensa preocupación que nos crea caer en una peligrosa "sociedad subsidiada" mediante la cual se fomente el ocio y la inactividad, y el dejar pasar sencillamente porque todo nos llega.

Este tipo de sociedad es muy peligrosa, pues el día que se acaban los subsidios por cualquier razón, queda al descubierto el verdadero problema social, como lo estamos percibiendo en países muy vecinos al nuestro, donde la gente sencillamente ya no quiere trabajar ni ser productiva.

\section{CONCLUSIONES}

Es evidente que un buen sistema de seguridad social es el mejor remedio contra la inequidad y la pobreza absoluta.

Es igualmente innegable que esto se fundamenta bajo sistemas sólidos de financiamiento que no pueden depender solamente de la tributación, pues a la postre conlleva el empobrecimiento de la clase media, que para no decir mentiras, es la que paga la carga impositiva.

Cada día es más evidente en nuestras sociedades la situación de empobrecimiento de la clase media, precisamente, por el desempleo de jóvenes que deberían reemplazar a quienes han laborado toda la vida y con el agravante de que esos "NiNis" (como se les llama hoy porque ni estudian ni trabajan), viven frustrados; además de que podrían a llegar a manejar altos índices de inconformidad y cuestionamiento a la sociedad que nada les ofrece, a pesar de estar capacitados e inclusive sobrecapacitados.

Se vive entonces en los hogares de las pensiones de los padres y de los abuelos, ante una generación nueva capacitada expectante, pero si no acuden al emprendimiento no podrán generar sus propios ingresos.

\footnotetext{
MendizÁbal Bermúdez, Gabriela. Condiciones de Trabajo y Seguridad Social. México, D.F.: Universidad Nacional Autónoma de México, 2012.

5 Cortés GonzÁlez, Juan Carlos, op. cit. (n. 3).
} 